Research Article

\title{
Long-term Follow-up of Multidrug Resistant Tuberculosis Patients of Delhi, Who had Received DOTS Plus Treatment along with Home Care and Counseling
}

Joyce F Vaghela', Tanu Anand ${ }^{2}$

\begin{abstract}
${ }^{1}$ Senior Consultant and HOD, Community Health Department, St. Stephen's Hospital, Sunder Nagari, Delhi, India. ${ }^{2}$ Scientist D (Medical), Department of Health Research, Indian Council for Medical Research, Ministry of Health \&amp; Family Welfare, Red Cross Road, New Delhi, India.
\end{abstract}

DOI: https://doi.org/10.24321/0019.5138.202015

I $\mathbf{N}$ F O

Corresponding Author:

Joyce F Vaghela, Community Health Department, St. Stephen's Hospital, Sunder Nagari, Delhi, India.

E-mail Id:

joycevaghela@gmail.com

Orcid Id:

https://orcid.org/0000-0001-7839-7501

How to cite this article:

Vaghela JF, Anand T. Long-term Follow-up of Multidrug Resistant Tuberculosis Patients of Delhi, Who had Received DOTS Plus Treatment along with Home Care and Counseling. J Commun Dis 2020; 52(2): 50-56.

Date of Submission: 2020-05-15

Date of Acceptance: 2020-07-02

\section{$\begin{array}{lllllllllllll}\mathbf{A} & \mathbf{B} & \mathbf{S} & \mathbf{T} & \mathbf{R} & \mathbf{A} & \mathbf{C} & \mathbf{T}\end{array}$}

Background: To realize the vision of a world free of TB, it becomes mandatory to disallow Ex-TB and Ex-MDR TB patients to have relapse or become Extremely Drug Resistant (XDR). Long follow-up of treated cases, who also received home care and counseling hasn't been done thus far in India.

Objective: To find out whether 50\% of Ex-MDR TB patients who had also received home based support with counseling are healthy after five years.

Methods: This retrospective study of 109 Ex-MDR-TB patients was carried out by Community Health Department (CHD) of a Tertiary Care Hospital in Delhi. They had received daily MDR Regimen (starting from August 2009 to August 2010 from their respective DOTS Providers) and home care and strong counseling support. They completed it by 2011 or 2012. The study period was from May to August 2015.

Result: After a long follow up of these patients in 2015 it was found that $71(65.14 \%)$ were alive \& healthy, $26(23.85 \%)$ dead, $5(4.59 \%)$ defaulters, $1(0.92 \%)$ failure cases, $4(3.67 \%)$ lost to follow-up, whereas $2(1.83 \%)$ were on treatment as they had relapsed.

Conclusion: Our study concludes that more than 50\% Ex-MDR TB cases who had also received home based support with counseling are alive \& healthy after five years. We recommend that a mechanism for homebased care \& counseling and Long Follow Up for MDR TB patients be developed.

Keywords: Follow-up through Neighbors, Physical Follow-up, SelfReporting, Telephonic Follow-up 


\section{Introduction}

The World Health Organization (WHO)/ International Union Against Tuberculosis and Lung Disease's global survey of resistance to anti-tuberculosis drugs in 1998 revealed that MDR TB is already a global pandemic, with focal "hot zones" of increased transmission in several countries, including Russia, Estonia etc. Failure to follow the WHO's guidelines was clearly associated with high rates of MDR TB. ${ }^{1}$ Specific measures are being taken within the Revised National Tuberculosis Control Programme (RNTCP) to address the MDR-TB problem through appropriate management of patients and strategies to prevent the propagation and dissemination of MDR- TB. ${ }^{2}$ The End TB Strategy 2016-2035 has a vision of a world free of TB, zero deaths, disease and suffering due to TB. ${ }^{3}$

It becomes mandatory to disallow treated TB and MDR TB patients to have relapse or become XDR cases if we have a vision of a world free of TB. Little is known about the long-term follow-up of patients treated for MDR-TB, including rates of relapse and chronic disability among cured persons. ${ }^{4}$ Long term ie five years or more follow-up of treated MDR-TB cases who also received home care and counseling hasn't been done thus far in India. Our hypothesis is that $50 \%$ of the MDR TB cases in Delhi, India who received Directly Observed Treatment Short-course Plus (DOTS Plus) and Home-based support with counseling are healthy after five years.

\section{Material and Methods}

Study Nature: It is a retrospective study.

Study Area: A resettlement and slum community located in North-east District of Delhi.

Study Period: The study was conducted from May to August 2015.

Study Population: 109 MDR-TB patients. These patients had received treatment along with home care and counseling support starting from August 2009 to August 2010, by Community Health Department (CHD) of a tertiary care hospital of Delhi.

\section{Inclusion and Exclusion criteria}

\section{The Inclusion Criteria}

- All MDR TB patients from Northeast, East, Central and West districts of Delhi, who had received DOTS Plus and home care \& counseling from August 2009 to August 2010.

- Patients whose follow up information could be collected directly- physically and/or telephonically and indirectly through contacting neighbors.

\section{The Exclusion Criteria}

- All MDR TB patients registered from August 2009 to
August 2010, in all the other Delhi districts besides Northeast, East, Central and West districts.

\section{Data Collection}

The Tool: A questionnaire was prepared and prê-tested before applying to the ex-patients. The questionnaire had questions related to socio-demography, present weight, co-morbidities, details of re-starting treatment for TB if any, family history of TB/MDR TB /XDR TB, h/o TB death in the family. Short Depression Scale was applied to all study participants to know their mental status.

Help of Home Care Support Teams: Two experienced mobile multi-disciplinary teams of home care providers - Health educator cum care giver and a team assistant cum care giver helped investigators in reaching ex-MDR patients' houses for collection of data. These teams were the ones that had actually done 'Home Care for MDR Patients' project from 2009 onwards. In those home visits 'Home Care' in the form of physical and mental support had been given through counseling about disease, hygiene and nutrition counseling, nursing care, and support at the time of Adverse Drug Reactions (ADRs). The teams had also helped these depressed, hopeless and weak MDR patients who were not confident of themselves by providing psychosocial support and encouraging them to do some work. The result was that the patients had re-started earning. School/college drop-out student patients were also supported psychologically and motivated so that they had got re-admitted into schools/ colleges.

Teams had also supported quite a few patients who were ignorant about Rs. 300/per month financial support under Govt. TB Scheme, in getting registered under this scheme. Though this was a small amount but it helped patients financially. With these kinds of support, Home Care for MDR TB patients' project had been able to prevent patients from becoming defaulters. Most of the patients had taken full course of DOTS Plus treatment. The details of the 'Home Care for MDR TB patients Project' and the teams are mentioned in our earlier study. ${ }^{5}$

In the year 2015 home-visits of 90 ex-MDR-TB patients were made who were alive in 2011-12.

The investigators started with the Physical \& Telephonic Interviews: The ex-MDR-TB patients were contacted either by home visit or telephonically in the months of May to August 2015. The questionnaires were filled. Those who could not be directly contacted their information was received through neighbors.

- Physical status: Treated MDR TB cases were asked to tell their present weight. If one of them did not know the present weight they were asked to weigh themselves on a weighing machine in the market for Rs. 2/- and inform their weight next day on phone. 
- Mental Status: Short Depression Scale was applied.

- History of co-morbidities and substance abuse: history of existing co-morbidities and substance abuse was also collected

- Details of re-starting treatment for TB: In case an expatient was re-started on TB treatment, all the details of it were taken from him/her.

- Details of other family members contracting TB/MDR TB /XDR TB: They were asked if anybody in the family had contracted disease.

- Details of any deaths in the family due to TB/MDR TB / Extensively Drug Resistant (XDR) TB were asked.

We were able to meet 57 ex-patients or their relatives whereas information of 33 was collected through neighbors as they had either rented other house or gone to villages (Table 1).

Table I.Follow-up information of 90 MDR TB Patients collected in 2015

\begin{tabular}{|c|c|c|c|}
\hline & Males & Females & Total \\
\hline $\begin{array}{c}\text { Patient or relative } \\
\text { contacted physically/ } \\
\text { Telephonically }\end{array}$ & 31 & 26 & 57 \\
\hline Neighbors contacted & 20 & 13 & 33 \\
\hline & 51 & 39 & 90 \\
\hline
\end{tabular}

Patient-wise files: The 'patient-wise records' were reviewed and 'ex-patients' present information (2015) was compared with first information of 2009-10 and second info of 201112.

Statistical analysis: In order to subject the data to statistical testing, the collected data was cleaned, and tabulated with frequency tables and percentages using MS-Excel. The values were reported as means $\pm S D$ for descriptive purposes. T-test was applied for BMI data and for Mental status data using Social Science Statistics Calculator. ${ }^{6}$ Relative-risk (between dead and alive groups) with $95 \%$ confidence intervals was calculated by using Medcalc Software bvba. ${ }^{7}$ A statistical test was considered significant when the $P$ value was $<0.05$.

Ethical Considerations: Institutional Review Committee approval was taken. Informed consent in Hindi was taken from all the MDR-TB patients.

\section{Result}

Our study showed that out of 109 ex-MDR patients in 2009 there were 63 (57.8\%) were males and 46 (42.2\%) females. In the year $2011-12,90$ remained as 12 males and 7 females died and by the time it was 2015 there were a total of 83 alive, 47 males and 36 females as 4 more males and 3 females had died making it a total of 26 dead (Table $2 \& 3$ ).

Table 2.MDR TB Patients in 2009, in $20 \mathrm{I} \mathrm{I-} 12$ and in 2015

\begin{tabular}{|c|c|c|c|c|c|c|c|c|c|}
\hline & \multicolumn{3}{|c|}{2009} & \multicolumn{3}{c|}{2011 to 12 } & \multicolumn{3}{c|}{2015} \\
\hline Age in years & Male & Female & Total & Male & Female & Total & Male & Female & Total \\
\hline$>10-20$ & 9 & 16 & 25 & 8 & 14 & 22 & 8 & 13 & 21 \\
\hline$>20-30$ & 20 & 16 & 36 & 18 & 14 & 32 & 17 & 13 & 30 \\
\hline$>30-40$ & 13 & 7 & 20 & 11 & 5 & 16 & 10 & 4 & 14 \\
\hline$>40-50$ & 9 & 4 & 13 & 7 & 3 & 10 & 5 & 3 & 8 \\
\hline$>50-60$ & 11 & 1 & 12 & 7 & 1 & 8 & 7 & 1 & 8 \\
\hline$>60-70$ & 1 & 2 & 3 & & 2 & 2 & & 2 & 2 \\
\hline & 63 & 46 & 109 & 51 & 39 & 90 & 47 & 36 & 83 \\
\hline
\end{tabular}

Table 3.MDR TB Patients died in $201 \mathrm{I}-12$ and in 2015

\begin{tabular}{|c|c|c|c|c|c|c|c|c|c|c|c|}
\hline & & & \multicolumn{3}{|c|}{ Patients dead in $\mathbf{2 0 1 1}$ to $\mathbf{1 2}$} & & \multicolumn{3}{|c|}{ Patients dead in 2015} & \\
Age in years & Male & Female & Total & $\mathbf{M}$ & $\mathbf{F}$ & Total Died & Alive & M & F & Total Died & Alive \\
\hline$>10-20$ & 9 & 16 & 25 & 1 & 2 & 3 & 22 & & 1 & $\mathbf{1}$ & 21 \\
\hline$>20-30$ & 20 & 16 & 36 & 2 & 2 & 4 & 32 & 1 & 1 & $\mathbf{2}$ & 30 \\
\hline$>30-40$ & 13 & 7 & 20 & 2 & 2 & 4 & 16 & 1 & 1 & $\mathbf{2}$ & 14 \\
\hline$>40-50$ & 9 & 4 & 13 & 2 & 1 & 3 & 10 & 2 & & $\mathbf{2}$ & 8 \\
\hline$>50-60$ & 11 & 1 & 12 & 4 & & 4 & 8 & & & 8 \\
\hline$>60-70$ & 1 & 2 & 3 & 1 & & 1 & 2 & & & & 2 \\
\hline & 63 & 46 & 109 & 12 & 7 & 19 & 90 & 4 & 3 & $\mathbf{7}$ & 83 \\
\hline
\end{tabular}


Table 4.Outcome of five year follow up of ex-MDR TB Patients

\begin{tabular}{|c|c|c|c|c|c|c|c|c|}
\hline & \multicolumn{3}{|c|}{ Treatment outcome in $\mathbf{2 0 1 1}$ to 2012 } & \multicolumn{3}{c|}{ Follow-up outcome in 2015 } \\
\hline & Males & Females & \multicolumn{2}{|c|}{ Total (n, \%) } & Males & Females & \multicolumn{2}{|c|}{ Total (n, \%) } \\
Cured & 45 & 34 & 79 & 72.48 & 39 & 32 & 71 & 65.14 \\
\hline Dead & 12 & 7 & 19 & 17.43 & 16 & 10 & 26 & 23.85 \\
\hline Default & 4 & 2 & 6 & 5.50 & 3 & 2 & 5 & 4.59 \\
\hline Failure \& XDR & 2 & 3 & 5 & 4.59 & & 1 & 1 & 0.92 \\
\hline Don't know & & & & & 3 & 1 & 4 & 3.67 \\
\hline On Rx due to relapse & - & - & - & & 2 & - & 2 & 1.83 \\
\hline & 63 & 46 & 109 & 100.00 & 63 & 46 & 109 & 100.00 \\
\hline
\end{tabular}

Table 5.BMI of ex-MDR TB Patients at the start of treatment, at completion of treatment and after five year follow-up

\begin{tabular}{|c|c|c|c|c|c|c|}
\hline & \multicolumn{2}{|c|}{$\begin{array}{c}\text { At start of treatment } \\
\text { (2009) }\end{array}$} & \multicolumn{2}{c|}{$\begin{array}{c}\text { At completion of } \\
\text { treatment (2011-12) }\end{array}$} & \multicolumn{2}{c|}{$\begin{array}{c}\text { After five year } \\
\text { follow-up (2015) }\end{array}$} \\
\hline$<18.5$ & 73 & 66.97 & 58 & 53.21 & 13 & 11.93 \\
\hline$>18.5-24.9$ & 22 & 20.18 & 30 & 27.52 & 23 & 21.1 \\
\hline$>24.9$ & & & 2 & 1.83 & 10 & 9.17 \\
\hline Dead & 5 & 4.59 & 10 & 9.17 & 26 & 23.85 \\
\hline $\begin{array}{c}\text { Defaulter / Don't Know (House Locked) } \\
\text { and/or Loss-To-Follow-Up (LFU) }\end{array}$ & 9 & 8.26 & 9 & 8.26 & 37 & 33.94 \\
\hline & 109 & 100.00 & 109 & 100.00 & 109 & 100.00 \\
\hline
\end{tabular}

Table 6.Co-morbidities among 109 MDR Patients

\begin{tabular}{|c|c|c|c|c|c|}
\hline Co-morbidities & & In Dead & In Alive & Relative Risk (RR) [95\% Cl] & P-value \\
\hline \multicolumn{6}{|l|}{ Diabetes } \\
\hline Yes & 11 & 3 & 8 & 1.1971 & \\
\hline No & 98 & 23 & 75 & 0.3424 to 4.1854 & 0.7782 \\
\hline \multicolumn{6}{|l|}{ COPD } \\
\hline Yes & 7 & 4 & 3 & 4.2564 & \\
\hline No & 102 & 22 & 80 & 1.0179 to 17.7987 & 0.0472 \\
\hline \multicolumn{6}{|l|}{ Tobacco Use } \\
\hline Yes & 30 & 10 & 20 & 1.6458 & \\
\hline No & 79 & 16 & 63 & 0.8430 to 3.2132 & 0.1444 \\
\hline \multicolumn{6}{|c|}{ Alcohol consumption } \\
\hline Yes & 21 & 6 & 15 & 1.2769 & \\
\hline No & 88 & 20 & 68 & 0.5523 to 2.9521 & 0.5675 \\
\hline \multicolumn{6}{|l|}{ HIV } \\
\hline Yes & 2 & 1 & 1 & 3.1923 & \\
\hline No & 107 & 25 & 82 & 0.2068 to 49.2731 & 0.4058 \\
\hline
\end{tabular}


Outcome: After a long follow up of these patients in 2015 it was found that 71 (65.14\%) were alive \& healthy, 26 (23.85\%) dead, 5 (4.59\%) defaulters, 1 (0.92\%) failure case, 4 (3.67\%) don't know/lost to follow-up, whereas 2 (1.83\%) were on treatment as they had relapsed (Table 4).

Health status: Patients having Body Mass Index (BMI) $<18.5$ were 73 (55.97\%), 58(53.21\%) and 13 (11.93\%) in the years 2009, 2011-12 and 2015 respectively. There were no patients with BMI of $>24.9,2$ (1.83\%) and $10(9.17 \%)$ in the years 2009, 2011-12 and 2015 respectively. This data shows that their health status had improved considerably by the year 2015 (Table 5).

The mean weight of the study patients in 2009 was $43 \pm 8.73 \mathrm{Kg}$ which showed significant improvement immediate post-completion of treatment i.e. in 2011or 2012 (mean=46.44 $\pm 10.15 ; p=0.00001, t=-5.526)$. Further, 'weight in 2015' showed a highly statistically significant difference (mean=54.95 $\pm 28.07 ; p=0.00001, t=-9.248$ ) when compared to initiation of treatment in 2009.

Mental status: The depression level was high while on treatment i.e. in 2009 and 2010 (mean=8.08 23.4 ) but it came down immediately post completion of treatment ( mean=7.02 \pm 3.08 ; $p$-value $=0.0042, t-2.595$ ) in 2011 and 2012. The same became extremely low in 2015 when compared to initiation of treatment in 2009. (mean=2.53 \pm 3.19 ; $p$-value $<0.00001, t-8.233$ ), which was highly statistically significant.

\section{Co-morbidities and substance abuse}

Out of 109 patients 11 (7 males \& 4 females) were Diabetics, 7 COPD cases, 2 had HIV, 30 were smokers, and 21 used to consume Alcohol. Except for Diabetes rest of the comorbidities were found only in males. Inter groups - 'dead and alive' the difference for Chronic Obstructive Pulmonary Disease (COPD) $p=0.04$; $R R=4.25 ; 95 \% \mathrm{Cl}=1.01-17.79$ was found to be statistically significant (Table 6).

Details of re-starting treatment for TB: Two cases had relapsed and were taking DOTS Plus treatment at the time of study (one on 22.9.2014 with Registration number 318/14 and another on 08.06.2015 with Registration number $182 / 15)$. Both these patients were males and aged $>40$ years in 2009 when they had started MDR treatment.

Details of other family members contracting TB/MDR TB /XDR TB or dying due to it: It was found that $4(4.8 \%)$ family members had TB. At the time of study 3 were on CAT I treatment and 1 was already cured. There were no deaths reported in the family members.

\section{Discussion}

The information on post treatment status of the MDR-TB patients remains largely unknown in India. Our study of 109 MDR patients was an attempt in this regard. The age and gender wise distribution of study participants followed the same pattern as evidenced by research elsewhere. Generally, the prevalence of TB is higher among males in comparison to females. ${ }^{8}$

Our study reported that $72.48 \%$ of patients in 2011 and 2012 and $65.14 \%$ patients in 2015 remained cured. This finding is slightly higher than that of observed treatment success estimate up to $62 \%$ found in a systematic review across all studies that used second line drugs in individualized or standardized protocols. ${ }^{9}$ This higher favorable long-term outcome in the current study could be due to the fact that patients also received home care and counseling which has shown to ensure compliance and adherence to treatment in TB patients. ${ }^{10,11,12}$ The present study also showed lower relapse rate among MDR TB patients (1.83\%) which is assumed to be due to the home based care. In our study we found higher mortality among MDR-TB patients who defaulted or failed during treatment, this is comparable to a study by He GX. ${ }^{13}$ We could not interact with 37 patients as they were Loss-To-Follow-Up (LFU). An Indian study has described a plethora of characteristics associated with LFU. ${ }^{14}$

Tuberculosis is a wasting disease and cachexia is more profound with MDR-TB. The mechanisms involved in weight loss are not well known. ${ }^{15}$ Nutritional assessment and regular monitoring of nutritional state are essential for successful management of MDR-TB cases. ${ }^{16}$ In the present context, the ex-patients showed significant weight gain during post treatment follow up as nutrition counseling and monitoring was integral part of home based care.

TB is associated with psychiatric morbidity, particularly depressive disorder, and this has been recognized as a cause of poor compliance and a cause of increased morbidity and mortality from the disease. ${ }^{17}$ Our study revealed higher depression score in MDR TB patients while they were undergoing DOTS plus treatment. Once they were declared cured the depression levels started coming down and by 2015 levels were significantly low.

The commonest co-morbid condition associated with MDR TB patients in our study was Diabetes. High frequency of diabetes as a co-morbidity among MDR-TB patients is a known fact. ${ }^{18}$ We found Chronic Obstructive Pulmonary Disease (COPD) as the second common morbidity and it was significantly associated with the death of patients. A study in India, also found the restrictive type of obstruction and pure obstruction as cause of death. ${ }^{19}$ Other studies also found association between signs of severe protracted disease ... as factors associated with poor outcome. ${ }^{20}$

\section{Conclusion}

Strengths and limitations: Our study concludes the hypothesis that $>50 \%$ of cases of MDR TB in Delhi who received home based support with counseling are physically 
and mentally healthy after five years of registration under DOTS Plus. The great strength of this study is its novelty as our MDR TB patients had also received home care and counseling. Pre-tested study tool was used for data collection and every effort was made to reduce attrition and gather maximum information. However, the study is not without limitations. Selection of patients from a few districts of Delhi may limit its external validity. Also there was a big number, which could not be contacted directly. Further, to study the effectiveness of home care and counseling in MDR-TB, a comparison group may be taken. Limitations with standing, the study highlights the role of home care and counseling in improved five year survival of MDR TB patients. We recommend that a mechanism for homebased care \& counseling and Long Follow Up for MDR TB patients be developed.

\section{Acknowledgments}

The authors would like to thank the two teams of home care providers who helped investigators in reaching ex-MDR patients' houses for collection of data.

\section{Sources of Funding}

This study was possible as the Community Health Department of St. Stephen's Hospital Delhi received funding for a project called 'Home Care for MDR Patients'. This project was funded by Eli Lilly through United Way Worldwide. We acknowledge their financial support. The funders had no role in study design, data collection and analysis, decision to publish or preparation of the manuscript.

\section{Conflict of Interest: None}

\section{Refrences}

1. Farmer P, Kim JY. Community based approaches to the control of multidrug resistant tuberculosis: introducing "DOTS-plus". BMJ 1998; 317: 671-674 Available from: https://www.ncbi.nlm.nih.gov/pmc/ articles/PMC1113843/ accessed on 15.5.2020.

2. Central Tuberculosis Division, Directorate General of Health Services, MOH \& FW. RNTCP Guidelines on Programmatic Management of Drug Resistant TB (PMDT) in India [Internet] 2012 [Accessed on 2020 May 15]. Available from: https://tbcindia.gov. in/.../8320929355Guidelines\%20for\%20PMDT\%20 in\%20India\%.

3. Uplekar M, Weil D, Lonnroth K, Jaramillo E, Lienhardt C, Dias HM et al. WHO's new End TB Strategy. Lancet 2015;385(9979):1799-801. http://dx.doi.org/10.1016/ S0140--6736(15)60570--0. [Accessed on 2020 May 15]. Available from: https://pubmed.ncbi.nlm.nih. gov/25814376/.

4. Shin SS, Furin JJ, Alcantara F, Bayona J, Sanchez E, Mitnick CD. Long-term follow- up for multidrugresistant tuberculosis. Emerging Infectious Diseases
2006;12:687- 88 [Accessed on 2020 May 15]. Available from: https://www.ncbi.nlm.nih.gov/pmc/articles/ PMC3294679/.

5. Vaghela JF, Kapoor SK, Kumar A, Dass RT, Khanna A, Bhatnagar A. Home based care to multi-drug resistant tuberculosis patients: A pilot study. IJT 2015; 62: 91-96. [Accessed on 2020 May 15]. Available from: https:// pubmed.ncbi.nlm.nih.gov/26117478/.

6. Social Science Statistics Calculator. [Accessed on 2020 May 6]. Available from: https://www.socscistatistics. com/tests/studentttest.

7. MedCalc statistical software. [Accessed on 2020 May 6]. Available from: www.medcalc.org.

8. Chakaroborty AK. Epidemiology of Tuberculosis-Current status in India. IJMR 2004; 20(10): 248-276. [Accessed on 2020 May 15]. Available from: https://pubmed.ncbi. nlm.nih.gov/15520481/.

9. Orenstein EW, Basu S, Shah SN, Andrews JR, Friedland GH, Moll AP et. al. Treatment outcomes among patients with multidrug-resistant tuberculosis: systematic review and meta-analysis. Lancet Infect Dis 2009; 9: 153-161. [Accessed on 2020 May 15]. Available from: https://www.clinicalkey.com/\#!/content/ playContent/1-s2.0-S1473309909700416?returnurl=https:\%2F\%2Flinkinghub.elsevier.com\%2Fretrieve\%2Fpii\%2FS1473309909700416\%3Fshowall\%3Dtrue\&referrer=https:\%2F\%2Fpubmed.ncbi.nlm. nih.gov\%2F19246019\%2F.

10. Miti S, Mfungwe V, Reijer P, Mahers D. Integration of tuberculosis treatment in a community-based home care for persons living with HIV/AIDS in Ndola, Zambia. Int J Tubercul Lung Dis 2003; 7(9 Suppl 1): S92-98. [Accessed on 2020 May 13]. Available from: https:// pubmed.ncbi.nlm.nih.gov/12971660/.

11. Kangangi JK, Kibuga D, Muli J, Maher D, Billo N, N'gang'a L et al. Decentralisation of tuberculosis treament from the main hospitals to the peripheral health units and in the community within Machakos District, Kenya. Int J Tubercul Lung Dis 2003; 7(9 Suppl 1): S5-13. [Accessed on 2020 May 15]. Available from: https://pubmed.ncbi. nlm.nih.gov/12971649/.

12. Adatu F, Odeke R, Mugenyi M, Gargioni G, McCray E, Schneider E et al. Implementation of the DOTS strategy for tuberculosis control in rural Kiboga District, Uganda: Offering patients the option of treatment supervision in the community, 1998-1999. Int J Tubercul Lung Dis 2003; 7(9 Suppl 1): S63-71. [Accessed on 2020 May 14]. Available from: https://pubmed.ncbi.nlm.nih. gov/12971656/.

13. He GX, Xie YG, Wang LX, Borgdorff MW, van der Werf MJ, Fan Ji H et al. Follow-Up of Patients with Multidrug Resistant Tuberculosis Four Years after Standardized First-Line Drug Treatment. PLOS ONE 2010; 5(5): 
e10799. doi:10.1371/journal.pone.0010799. [Accessed on 2020 May 15]. Available from: https://pubmed. ncbi.nlm.nih.gov/20520720/.

14. Shringarpure KS, Isaakidis P, Sagili KD, Baxi RK. LossTo-Follow-Up on Multidrug Resistant Tuberculosis Treatment in Gujarat, India: The WHEN and WHO of It. PLoS ONE 2015; 10(7): e0132543. DOI:10.1371/journal. pone.0132543. . [Accessed on 2020 May 14]. Available from: https://pubmed.ncbi.nlm.nih.gov/26167891/.

15. Beutler B, Greenwald D, Hulmes D, Chang M, Pan YC, Mathison $\mathrm{J}$ et al. Identity of tumor necrosis factor and the macrophage-secreted factor cachectin. Nature 1985; 316: 552-554. [Accessed on 2020 May 12]. Available from: https://pubmed.ncbi.nlm.nih. gov/2993897/.

16. Sharma SK, Mohan B. Multi-Drug Resistant Tuberculosis. Ind J Med Res 2004; 120(10); 354-376. [Accessed on 2020 May 13]. Available from: https://pubmed.ncbi. nlm.nih.gov/15520486/.

17. Issa BA, Yussuf AD, Kuranga SI. Depression co-morbidity among patients with tuberculosis in a university teaching hospital outpatient clinic in Nigeria. Ment Health Fam Med 2009; 6(3): 133-138. [Accessed on 2020 May 13]. Available from: https://www.ncbi.nlm. nih.gov/pmc/articles/PMC2838651/.

18. Chung-Delgado K, Guillen-Bravo S, Revilla-Montag A, Bernabe-Ortiz. Mortality among MDR-TB Cases: Comparison with Drug-Susceptible Tuberculosis and Associated Factors. PloS One 2015; 10(3): e0119332. DOI: 10.1371/journal.pone.0119332, PMCID: PMC4366185. [Accessed on 2020 May 15]. Available from: https://www.ncbi.nlm.nih.gov/pmc/articles/ PMC4366185/.

19. Singla N, Singla R, Fernandes S, Behera D. Post treatment sequelae of multi-drug resistant tuberculosis patients. Ind J Tuberc 2009; 56: 06-12. [Accessed on 2020 May 15]. Available from: https://pubmed.ncbi.nlm.nih. gov/20469732/.

20. Mitnick C, Bayona J, Palacios E, Shin S, Furin J, Alcantara F et al. Community-Based Therapy for MultidrugResistant Tuberculosis in Lima, Peru. N Engl J Med 2003; 348: 119-128. [Accessed on 2020 May 15]. Available from: https://pubmed.ncbi.nlm.nih.gov/12519922/. 